\title{
A simple approach to the management of service risk in a local mental health service
}

\section{Mark Davies}

Risk, and how to manage risk, have become dominant themes of this decade. Risk is essentially any feature of an organisation which is likely to prevent that organisation from achieving its primary aims (Rosen, 1995). In general, the lower the risk in an organisation, the higher the performance of that organisation is likely to be. In turn this can lead to more efficient use of resources. In the area of mental health, the consequences of risk can be serious, this being amply demonstrated by the public inquiries into homicides by mentally disordered people. Such inquiries consistently reveal inadequacies in local services providing mental health care (Appleby, 1997). The identification and management of risk within local mental health services has therefore become a priority. Clinicians as managers have a key role in such a development, particularly with the introduction of clinical governance (Oyebode et al, 1999). This paper outlines a simple approach to risk management in a local mental health service.

\section{Risk}

Risk first came to prominence in the area of mental health from two main sources. In the clinical field, concern over homicides and suicides by mentally ill people in the community has led to criticism of local services. Various aspects of these services have been highlighted as being at fault, including training, communication and resource availability (Appleby, 1997). On the other hand, risk awareness in the administrative field has largely developed out of medico-legal events in which various health care organisations have had to pay out large sums of money to cover claims made against them for failure in standards of care. However, the negative consequences that could be generated by a local mental health service are not just the serious, high-profile cases described above. Others range from a minor drug side-effect, to computer system malfunction, to high numbers of staff being on sick leave through low morale. These all contribute to the overall risk load of the local mental health service system, and may make the more serious undesirable outcomes more likely.

A successful risk management policy therefore needs to take a holistic view of risk as being a potential feature of the whole organisation. The organisation, in this case a local mental health service, is in turn composed of components which themselves may contain appreciable risk factors. From the above definition risk in a local mental health service is any feature of the service which is likely to prevent that service from fulfilling its aim. Risk management therefore begins with the analysis of an organisation into its component parts (Cooke \& Slack, 1991). Each component can then be assessed for possible contribution of risk to the whole organisation. A suggested classification for local mental health service components is outlined in Table 1 , along with examples of associated factors which can contribute to the intrinsic risk of each component.

\section{Risk management}

Having identified the components of a local mental health service, and the related potential risk factors, a general approach to risk management of such a service can be developed. In developing a management policy of any kind, an infrastructure must first be formed with the function of developing and maintaining that policy. As risk management should be a top priority for a local service, this means an appropriate infrastructure should involve the 'key players' in that service, including for example, the medical director, business manager, other clinical managers, and an audit coordinator. Once the infrastructure is in place, the control capabilities of the risk management team must be clear. Some factors are not controllable internally, but rather depend on external control (Cooke \& Slack, 1991). Government directives. for example, are not necessarily risk-free, either because of inadequate design or precipitous implementation. Risk may then be introduced 


\section{REVIEW ARTICLES}

Table 1. Risk analysis - components and examples of associated risk factors in a local mental health service

\begin{tabular}{ll}
\hline Service component & Example of risk foctors \\
\hline Staff & Inadequate training \\
Process & Lw morale \\
Information systems & Lack of guidelines (clinical and administrattve) \\
& Subject unresearched nationally/internationally \\
Accommodation & Unsultable software \\
Resource use & Obsolete hardware \\
Monitoring systems & Lack of maintenance \\
Communication for clinical use & Insufficient external funding \\
Inappropriate allocation & Lack of interest in audit \\
Component integration & No allocated manager \\
& No agreed interface with external agencies \\
& No agreed internal system \\
& Unclear roles in relation to overall service \\
\hline
\end{tabular}

into the service when these directives are incorporated locally. Other examples include lack of national research, lack of external funding, and shortages of potential applicants for service posts. These sources of potential risk need to be explicitly acknowledged, even though they may not be directly manageable within the service.

Having identifled who will manage risk, and what aspects of a local service are manageable, the circumstances under which a component could be said to contain risk need to be determined. Riskfree organisations tend to exist only in the mind of theoreticians. In practice, therefore, organisations tend to aim for risk tolerance. In a local service, risk tolerance may exist in which the level of risk is not significant enough to be considered unreasonable. The problem then is to decide what constitutes 'reasonable risk'. Reasonable risk is a relattve state in which pre-set standards define the state of affairs of a service consistent with a tolerable risk level. These pre-set standards are referred to as 'benchmarks'. Benchmarks have been developed as a means of setting and monitoring the performance of local mental health services as a whole, using performance indicators such as the Health of the Nation Outcome Scales system (Wing. 1995).

However, measuring service performance does not necessarlly give an accurate indication of overall service risk. Poor performance is only a possible consequence of risk, not a necessary one. This means that a good service performance can still be associated with significant service risk. Very low levels of risk in one component may be masking substandard risk levels in another. Alternatively, risk may exdst just below a threshold at which performance could be affected. For example, overworked staff may generate high performance until a relatively minor extra demand is made on the service, when performance may fall sharply below standard. The risk created in this situation could not have been predicted by the performance indicators alone. However, as performance indicators move from service assessment to component assessment, such indicators are more likely to expose potential risk factors. This is because component-associated risk factors are more likely to coincide with the factors considered important in component performance; for example, staff training (potential risk factor) in relation to staff appraisal (performance indicator). Benchmark development for individual service components has been initiated, an example being the Clinical Standards Advisory Group (Wing, 1995). One of the remits of the proposed National Service Frameworks will be to develop this field further (Department of Health. 1998).

For the moment, though, there is no agreed integrated template for component standards. This means that local services may have to develop their own standards for components of the service, based on 'best-available evidence'. This would include gathering guidelines from existing agencies, such as professional organisations and government bodies, to provide a foundation for the development of local standards. The process of developing these standards would include ensuring that component standards were consistent and integrated with one another, in other words, a 'good fit'. Once standards are clearly identified for each component, there must be implementation of change to bring components up to these set standards. Monitoring systems, such as regular internal audit, must then be introduced to ensure that these standards are maintained (Firth-Cozens, 


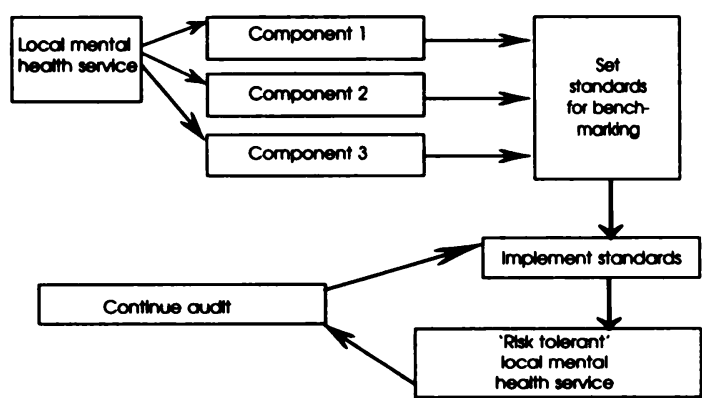

Fig. 1. Steps in the risk management of a local mental health senice.

1993). This process can be represented diagrammatically (see Fig. 1).

An example of service risk management in practice might be in the area of resource allocation. In a local mental health service, the case loads for community psychiatric nurses (CPNs) need to be limited to a standard maximum number, taking into account casemix and population covered, in order for a particular CPN to safely manage that case load. When resource allocation is inadequate, in this case insufficient funding for the correct number of CPNs for that local area, CPN case loads will be above the standard set for safe case-load management. Adverse events are now more likely as a direct result of unsafe case-load numbers. This will consequently introduce intolerable risk into this component of the service. Risk management here would Involve being aware of the standard for safe case-loads, acknowledging sub-standard conditions resulting in intolerable risk, leading to steps to reduce risk to tolerable levels by increasing funding. If further resources are not available, perhaps through external resource restriction, the inability to internally control this continuing risk needs to be acknowledged and recorded. Case-loads are then monitored and reviewed at regular intervals to ensure numbers are within set stan- dards, and risk is maintained at a tolerable level.

\section{Comment}

Risk management is now an essential feature of all local mental health services. A clear strategy with all concerned working in cooperation is implicit in successful development of a risk management policy. Once the components of local mental health services have been identified, agreed standards for the reduction of risk within these components need to be developed, both locally and nationally. When a local service undertakes risk management. it is essential that a formal infrastructure exists with a clear strategy and sufficient resources to develop an effecttve policy. A risk strategy must be developed alongside general service strategies, and be reviewed formally on a regular basis. This is particularly relevant in view of the recent introduction of clinical governance as a means of managing local services.

\section{References}

APPLEBLY, L. (1997) National Confidential Inquity into Suicide and Homicide by People with Mental Iiness. London: Department of Health.

COOKE, S. \& SLACK, N. (1991) Makdng Management Decisions, 2nd edn. Hemel Hempstead: Prentice Hall Europe (Academic).

Department of Henlth (1998) Modernising Mental Health Services. London: The Stationery Office.

FIRTH-CozEns, 1. (1993) Audit in Mental Health Services. Hove: Lawrence Erlbaum Assoclates.

OYEBOde, F., BROWN, N. \& PARRY, E. (1999) Clinical governance: application to psychiatry. Psychiatric Bulletin. 23, 7-10.

Rosen, R. (1995) Strategic Management. An Introduction. London: Pitman Publishing.

WING. J. K. (ed) (1995) Measurement for Mental Health. Contributions from the College Research Unit. London: Royal College of Psychiatrists.

M. Davies, Specialist Registrar, Kings Park Community Hospital, Gloucester Road, Boscombe. Bournemouth, Dorset BH7 GJE 